\title{
A Study to Assess the Stress among Antenatal Women Admitted for Safe Confinement at a Tertiary Level Hospital, Thiruvananthapuram, Kerala
}

\author{
Gayathri Krishna ${ }^{1}$, Aswathy S R $\mathbf{R}^{2}$, Arathy Lal S ${ }^{3}$, Anju Mariam Punnoos ${ }^{4}$, \\ Devadathan $V^{5}$, Jeena L Victor ${ }^{6}$, Jyothis Prakash ${ }^{7}$, Aiswarya LP ${ }^{8}$, Aswathy KL ${ }^{9}$ \\ ${ }^{1-6}$ BSc Nursing, Government College of Nursing, Medical College, Thiruvananthapuram, Kerala-695011 \\ ${ }^{7-8}$ Lecturer, Government College of Nursing, Medical College, Thiruvananthapuram, Kerala-695011 \\ ${ }^{9}$ Assistant Professor, Government College of Nursing, Medical College, Thiruvananthapuram, Kerala-695011
}

Corresponding Author: Jyothis Prakash

\section{ABSTRACT}

Aim: To assess stress among antenatal women admitted for safe confinement and to find stress level and related factors for stress. Identifying the level of stress will help to develop interventions to reduce the stress.

Objectives:

i) To find out the level of stress experienced by antenatal women.

ii) To find out the association between level of stress and selected socio-demographic and clinical data of antenatal women.

Method: A quantitative research approachdescriptive cross-sectional survey design was adopted. 60 samples were selected for the study by using purposive sampling technique.

Results: It is identified that $1 \%$ of selected antenatal women had no stress, $73 \%$ had mild stress, 25\% had moderate stress and 1\% had severe stress. After calculation of chi square values, it is identified that there is association between stress level and selected sociodemographic variables (occupation) and also there is significant association between stress level and clinical data (parity).

Conclusion: Majority of women in their antenatal period experience varying stress. $73.33 \%$ of them had mild stress where as $26.66 \%$ experienced moderate stress. Extreme levels of stress including no stress and severe stress were very rare i.e., $1 \%$. Multiple factors have association with their stress level. Present study documented significant association with parity and occupational status of women.

Keywords: stress, antenatal women, safe confinement.

\section{INTRODUCTION}

Stress is a complex genetically determined pattern of response of the human physiology to a demanding situation. A women's experience of pregnancy and childbirth is almost likely affecting her role as mother. Any stress and emotional changes during pregnancy have long term address effects on herself and her child and it may interfere with mother infant attachment and child development. The maternal stress during antenatal period can have specific effect on cognitive and brain development outcome of foetus. The complex situation of stress during antenatal period affects the physiological and physical health in many ways in antenatal women. The present study aimed to assess stress among antenatal women admitted for safe confinement in the antenatal wards of Sree Avittom Thirunal Hospital Thiruvananthapuram, Kerala.

\section{LITERATURE REVIEW}

Pregnancy is recognized as a stressful event in a woman's life that needs 
enormous psychological adjustment. During pregnancy, the hormonal responses of both the hypothalamic pituitary adrenal (HPA) axis and the sympathetic nervous system to emotional and physical stressors are severely attenuated during pregnancy. ${ }^{1}$ Moreover, pregnant women will encounter mixed feelings of happiness, insecurity, and fear that lead to a great desire for support from their partner and/or family. The interrelation of these factors leads to an imbalance between allostatic stress, the demands of life, and individual adaptive capacity that pregnant women perceive as stress. ${ }^{1}$

Stress is defined as the feelings or thoughts that an individual has about how much a stress event or situation occurs at a given time or over a given period. ${ }^{2}$ Antenatal stress during pregnancy is common, with $78 \%$ experiencing low to moderate and $6 \%$ high stress. ${ }^{3}$ Prevalence of stress in pregnancy varies from $11.6 \%$ to $46.7 \% .^{4-7}$ However, there have been few worldwide reports of prevalence of antenatal stress.

Stress during pregnancy is clearly known to be associated with poor obstetric outcomes, including preterm birth, preterm delivery and low birthweight. ${ }^{8-11}$ Moreover, maternal stress during pregnancy can affect iron transfer and the iron status of infants at delivery, resulting in lower iron stores at birth, low erythrocyte iron, increasing the likelihood of Stage 1 iron deficiency at 1 year of age. ${ }^{12}$ In addition, stress also has a strong negative impact on the quality of life of pregnant women. ${ }^{13}$

There have been few reports of associated factors of antenatal stress despite the high prevalence and negative effects on maternal and neonatal health. Previous reports of factors associated with antenatal stress were varied and inconclusive, such as gravida, gestational age, family income, pregnancy intention, husband's employment status, medical co-morbidities, and family support. ${ }^{14-15}$ The variety of these factors depends on population, sample size, stressscreening tool, and cultural context.
Another study conducted at Manipal University to assess the stress among antenatal women in India revealed that there is no or mild stress level among antenatal women 107 (66.9\%) and moderate to severe stress in $53(33.3 \%)$ of them. A Statistically significant association was observed for gravida, education and monthly family income of antenatal women. ${ }^{16}$

\section{MATERIALS \& METHODS}

Research Approach: A quantitative research approach-descriptive crosssectional survey design was adopted.

Setting of the Study: The study was conducted in antenatal wards of Sree Avitham Thirunal Hospital, Thiruvanathapuram, Kerala. Sree Avittam Thirunal Hospital is a tertiary care referral hospital where most of the antenatal mothers are referred cases from community. As most of the antenatal mothers are referred cases, researchers assume that, they possess a high level of stress.

Sampling Technique and Sample Size: Purposive sampling technique was used in this study to select the antenatal women and present study sample size consists of 60 antenatal women admitted in antenatal wards.

\section{Sampling Criteria:}

- Inclusion Criteria: All Antenatal women admitted in Sree Avitam Thirunal Hospital for safe confinement in all trimester irrespective of their age, gestation, parity.

- Exclusion Criteria: Women with history of Psychiatric illness, women who didn't know the Malayalam language.

Data Collection Techniques: The tools used in the study were interview schedule to assess socio-demographic and clinical data and a stress assessment scale.

Tool 1: Interview schedule to assess sociodemographic and clinical data. It was done by two parts

- Part-1: Socio-demographic data

It includes variables like age, education, income, occupation, religion, 
marital status, type of marriage and place of residence.

\section{- Part-2: Clinical data}

It includes variables like weeks of pregnancy, number of antenatal visits, frequency, minor ailments of pregnancy, family history of illness, presence of comorbidities history of hospitalization and reason, presence of obstetric complications.

Tool 2: Stress Assessment Scale by Dr. Ambreen Kazi.

A-Z Stress Scale is a standardized stress scale for pregnant women in South Asian Context developed by Dr. Ambreen Kazi. Permission was obtained from the author. Tool consists of 25 statements with 5-point scale. Maximum score was 120 and minimum score was 0 .

\section{Statistical Analysis}

The data collected was entered in a Microsoft excel spreadsheet. Continuous variables were summarized as means and standard deviation, and categorical variables were summarized as percentages. ChiSquare test was used to find out association between stress level and selected sociodemographic variables. A p-value of $<0.05$ was taken as statistically significant.

\section{RESULT}

The data was collected from 60 antenatal women admitted in Sree Avitom Thirunal Hospital, were tabulated, analysed and interpreted using descriptive and inferential statistics. Stress of antenatal women was analysed using mean and standard deviation. Level of stress and its association with social variable were analysed in terms of chi-square test. The results have been presented below in tabular and graphical forms.

\section{Section 1: Socio-demographic data of antenatal women.}

\begin{tabular}{|l|l|l|}
\hline \multicolumn{3}{|l|}{ Table 1: Socio-demographic characteristics of antenatal women (n=60) } \\
\hline Age & Number & Percentage (\%) \\
\hline$\leq 20$ & 11 & 18 \\
\hline $21-25$ & 16 & 27 \\
\hline $26-30$ & 21 & 35 \\
\hline$\geq 31$ & 12 & 20 \\
\hline Educational Status & & \\
\hline Primary education & 0 & 0 \\
\hline Schooled & 13 & 21.67 \\
\hline Higher secondary education & 25 & 41.67 \\
\hline Degree/Diploma & 20 & 33.33 \\
\hline Professional & 2 & 3.33 \\
\hline Occupation & & \\
\hline Home maker & 50 & 83.33 \\
\hline Business & 0 & 0 \\
\hline Private employee & 4 & 6.67 \\
\hline Manual labour & 1 & 1.67 \\
\hline Skilled labour & 0 & 0 \\
\hline Office Job & 5 & 8.33 \\
\hline Monthly Income & & \\
\hline Below 1000 & 53 & 88.33 \\
\hline 1000-5000 & 4 & 6.67 \\
\hline Above 5000 & 3 & 5 \\
\hline Family Structure & & \\
\hline Nuclear family & 29 & 48.33 \\
\hline Joint family & 31 & 51.67 \\
\hline Religion & & 65 \\
\hline Hindu & 39 & 15 \\
\hline Christian & 9 & 20 \\
\hline Muslim & 12 & \\
\hline Marriage & & \\
\hline Arranged & 53 & \\
\hline Self-selected & 7 & \\
\hline Type of Marriage & & \\
\hline Consanguineous & & \\
\hline Non-consanguineous & & \\
\hline
\end{tabular}


Gayathri Krishna et.al. A study to assess the stress among antenatal women admitted for safe confinement at a tertiary level hospital, Thiruvananthapuram, Kerala.

\begin{tabular}{|l|l|l|}
\hline \multicolumn{3}{|c|}{ Table 1 continued... } \\
\hline Marital Status & 52 & \\
\hline Stays with Partner & 7 & 86.67 \\
\hline Partner Abroad & 1 & 11.67 \\
\hline Divorced & & 1.67 \\
\hline Locality & 7 & \\
\hline Corporation & 4 & 11.67 \\
\hline Municipality & 49 & 6.67 \\
\hline Panchayat & 81.67 \\
\hline
\end{tabular}

\section{Section 2: Clinical data of antenatal women}

Table 2: Clinical data of antenatal women $(\mathrm{n}=\mathbf{6 0})$

\begin{tabular}{|l|l|l|}
\hline Gestational Age & Number & Percentage (\%) \\
\hline
\end{tabular}

\begin{tabular}{|l|l|l|}
\hline First trimester & 2 & 3.33 \\
\hline
\end{tabular}

\begin{tabular}{l|l|l}
\hline Second trimester & 2 & 3.33 \\
\hline
\end{tabular}

Third trimester

Parity

Primigravida

Multigravida

Antenatal Visit

One

\begin{tabular}{l|l|l} 
Ane & 3 & 5 \\
\hline Two & 2 & 3.3 \\
\hline
\end{tabular}

\begin{tabular}{l|l|l} 
Two & 2 & 3.33 \\
\hline Three & 2 & 3.33
\end{tabular}

\begin{tabular}{l|l|l} 
& 2 & 3.33 \\
\hline Above three & 2 & 3.33
\end{tabular}

Above three

Frequency of antenatal visits

Regular

\begin{tabular}{l|l|l}
\hline Irregular & 28 & 46.67
\end{tabular}

Gestational problems

\begin{tabular}{|l|l|l}
\hline Gestational problems & & \\
\hline Present & 55 & 8.33 \\
\hline Absent & 5 & 91.67
\end{tabular}

Family History of Illness

Diabetes Mellitus

Hypertension

Asthma

Seizure

None

Complications

Gestational diabetes mellitus

Gestational hypertension

\begin{tabular}{|c|c|c|}
\hline Gestational diabetes mellitus & 17 & 26. \\
\hline Gestational hypertension & 14 & 23 \\
\hline Anemia & 4 & \\
\hline
\end{tabular}

\begin{tabular}{l|l|l} 
Anemia & 4 & 6.60
\end{tabular}

\begin{tabular}{l|l|l} 
& 1 & 1.60 \\
\hline
\end{tabular}

\begin{tabular}{|c|c|c|}
\hline Polyhydramnios & 5 & 8.30 \\
\hline
\end{tabular}

\begin{tabular}{|l|l|l}
\hline None & 5 & 33.30 \\
\hline
\end{tabular}

History of Any Abortions

\begin{tabular}{|l|l|l}
\hline Present & 17 & 28.40 \\
\hline
\end{tabular}

\begin{tabular}{l|l|l}
\hline Absent & 17 & 28.40
\end{tabular}

Planned Pregnancy

Planned

\begin{tabular}{|l|l|l|}
\hline Unplanned & 57 & 95 \\
\hline Type of Delivery Opting & 3 & 5 \\
\hline Vaginal delivery & & \\
\hline Caesarean delivery & 56 & 93.33 \\
\hline
\end{tabular}

\section{Section 3: Stress among antenatal women}

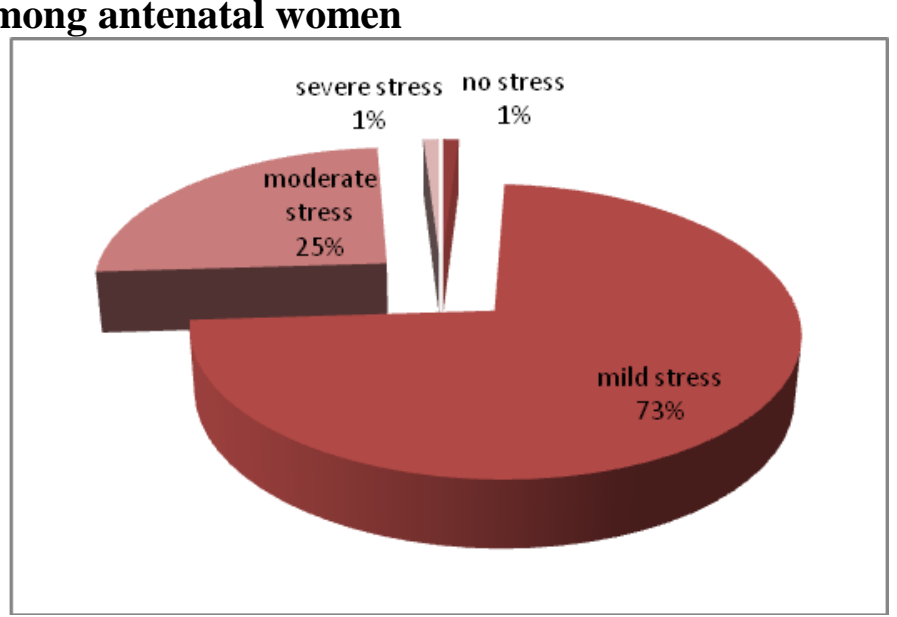

Figure 1: Distribution of mother according to the level of stress. 
Above figure shows that $73 \%$ had mild stress, $25 \%$ had moderate stress, $1 \%$ had severe stress and remaining $1 \%$ had no stress.

Section 4: Association between stress level and selected sociodemographic and clinical variables

\begin{tabular}{|l|l|l|l|l|}
\hline $\begin{array}{l}\text { Sl. } \\
\text { No }\end{array}$ & $\begin{array}{l}\text { Selected socio } \\
\text { demographic data }\end{array}$ & $\begin{array}{l}\text { Degree } \\
\text { freedom }\end{array}$ & $\begin{array}{l}\text { Chi } \\
\text { square }\end{array}$ & $\begin{array}{l}\text { p. } \\
\text { value }\end{array}$ \\
\hline 1 & Age & 1 & .4155 & $<0.05$ \\
\hline 2 & Occupation & 1 & 9.6236 & $<0.05$ \\
\hline 3 & Parity & 1 & 6.517 & $<0.05$ \\
\hline 4 & Complication & 1 & 3.140 & $<0.05$ \\
\hline
\end{tabular}

Table 3: As the value obtained on test statistics is greater than table value of chi-square for d.f. at 0.05 level of significance, null hypothesis is rejected. There is association between stress during antenatal period and selected sociodemographic variables and clinical variables.

\section{DISCUSSION}

Stress during pregnancy may lead to several problems to their mother and unborn child. Stress reacts physically, mentally and emotionally to the various conditions. The present study reveals that only $1 \%$ of antenatal woman had no stress, $73.33 \%$ had mild stress, $26.66 \%$ had moderate stress and remaining $1 \%$ had severe stress. Another study conducted by Maria, Pais et al to investigate stress in antenatal women among 160 mothers revealed that $33.1 \%$ had moderate to severe level of stress and $66.9 \%$ had no to mild level of stress respectively. ${ }^{17}$

Our study revealed stress of antenatal women had significant association with their occupation status and parity. A study on antenatal stress showed that antenatal women had moderate to severe stress and stress was significantly associated with gravidity, educational status and monthly family income, and antenatal women who are staying in nuclear family, it may be due to lack of family support. ${ }^{17}$

In our study, $81 \%$ of mothers were in third trimester, $15 \%$ of mothers were in second trimester and remaining 3\% were in first trimester. Another study conducted by B Prasad Babu to assess the level of stress during the first, second and third trimester identified that there is no difference in the level of stress among the pregnant women irrespective of their period of pregnancy. ${ }^{18}$

\section{CONCLUSION}

Stress during pregnancy is, "the imbalance that antenatal mother feels when she cannot cope with demands, which are shown both behaviourally and physiologically". The emotions and experiences during antenatal period impinge on her developing foetus. It can arise from various situations like her economic status, lack of knowledge or support, type of work, parity etc. Therefore, measures must be taken during the time of pregnancy like providing psychological support, ensuring regular antenatal check-ups, counselling, family support etc. to reduce the stress among antenatal women.

\section{Acknowledgement: None}

\section{Conflict of interest: None}

\section{Source of funding: None}

\section{Ethical approval: Approved}

\section{REFERENCES}

1. González-Ochoa R, Sánchez-Rodríguez EN, Chavarría A, Gutiérrez-Ospina G, RomoGonzález T. Evaluating stress during pregnancy: do we have the right conceptions and the correct tools to assess it? $J$ Pregnancy. 2018;1-20.

2. Phillips AC. Perceived Stress. In: Gellman MD, Turner JR, editors. Encyclopedia of Behavioral Medicine. New York, NY: Springer; 2013.

3. Woods SM, Melville JL, Guo Y, Fan MY, Gavin A. Psychosocial stress during pregnancy. Am J Obstet Gynecol. 2010; 202(1):61. e1-61. e7. doi: 10.1016/j.ajog.2009.07.041

4. Engidaw NA, Mekonnen AG, Amogne FK. Perceived stress and its associated factors among pregnant women in Bale zone Hospitals, Southeast Ethiopia: a cross-sectional study. BMC Res Notes. 2019;12(356):1-6. doi:10.1186/s13104-019$4383-0$ 
5. Ahmed AE, Albalawi AN, Alshehri AA, AlBlaihed RM, Alsalamah MA. Stress and its predictors in pregnant women: a study in Saudi Arabia. Psychol Res Behav Manag. 2017 ; 10:97-102. doi:10.2147/PRBM.S131474

6. Waqas A, Zubair M, Zia $S$, et al. Psychosocial predictors of antenatal stress in Pakistan: perspectives from a developing country. BMC Res Notes. 2020;13(160):1-6. doi:10.1186/s13104-020-05007-3

7. Yarube IU, Sani L, Saleh MIA, Alhassan AW. Assessment of perceived stress amongst primigravidae attending an ante natal clinic in Kano, Nigeria. J Afr Ass Physiol Sci. 2018;6(1):46-51.

8. Staneva A, Bogossian F, Pritchard M, Wittkowski A. The effects of maternal depression, anxiety, and perceived stress during pregnancy on preterm birth: a systematic review. Women Birth. 2015;28(3):179-193. doi: 10.1016/j.wombi. 2015.02.003

9. Tanpradit K, Kaewkiattikun K. The effect of perceived stress during pregnancy on preterm birth. Int J Womens Health. 2020; 12:287-293. doi:10.2147/IJWH.S239138

10. Rondo' PHC, Ferreira RF, Nogueira F, Ribeiro MCN, Lobert H, Artes R. Maternal psychological stress and distress as predictors of low birth weight, prematurity and intrauterine growth retardation. Eur $J$ Clin Nutr. 2003;57(2):266-272. doi: 10.1038/sj.ejen.1601526

11. Lima SAM, El Dib RP, Rodrigues MRK, et al. Is the risk of low birth weight or preterm labor greater when maternal stress is experienced during pregnancy? A systematic review and meta-analysis of cohort studies. PLoS One. 2018;13(7): e0200594. doi: 10.1371/journal.pone. 0200594

12. Rendina DN, Blohowiak SE, Coe CL, Kling PJ. Maternal perceived stress during pregnancy increases risk for low neonatal iron at delivery and depletion of storage iron at one year. J Pediatr. 2018; 200:166173.e2. doi: 10.1016/j.jpeds.2018.04.040

13. Lagadec N, Steinecker M, Kapassi A, et al. Factors influencing the quality of life of pregnant women: a systematic review. $B M C$ Pregnancy Childbirth. 2018;18(455):1-14. doi:10.1186/s12884-018-2087-4

14. Vijayaselvi R, Beck MM, Abraham A, Kurian S, Regi A, Rebekah G. Risk factors for stress during antenatal period among pregnant women in tertiary care hospital of southern India. J Clin Diagn Res. 2015;9(10):1-5.

15. Basharpoor S, Heydarirad H, Daryadel SJ, Heydari F, Givi HG, Kishore J. The role of perceived stress and social support among predicting anxiety in pregnant women. $J$ Holist Nurs Midwifery. 2017;27(2):9-16. doi: 10.18869/acadpub.hnmj.27.2.9

16. Zust B, Natwick L, Oldani A. Stress perception among rural and urban perinatal patients. Online J Rural Nurs Health Care. 2010;10(1):70-79. doi:10.14574/ojrnhc. v10i1.75

17. Pais M, Pai MV, Kamath A, George A, Noronhna JA, Nayak BS, et al. Stress among antenatal women in India. International Journal of Nursing Care. 2014;2(2):63-67.

18. Prasad B, Mohan S. Stress among pregnant women. Indian journal of health and wellbeing. 2012:3(3):754-756.

How to cite this article: Krishna G, Aswathy S $\mathrm{R}$, Arathy Lal $\mathrm{S}$ et.al. A study to assess the stress among antenatal women admitted for safe confinement at a tertiary level hospital, Thiruvananthapuram, Kerala. International Journal of Research and Review. 2021; 8(7): 391-396. DOI: https://doi.org/10.52403/ijrr. 20210756 